This is the author's final, peer-reviewed manuscript as accepted for publication. The publisher-formatted version may be available through the publisher's web site or your institution's library.

\title{
Sequence organization and evolutionary dynamics of Brachypodium-specific centromere retrotransposons
}

\author{
L. L. Qi, J. J. Wu, B. Friebe, C. Qian, Y. Q. Gu, D. L. Fu, and B. S. Gill
}

\section{How to cite this manuscript}

If you make reference to this version of the manuscript, use the following information:

Qi, L. L., Wu, J. J., Friebe, B., Qian, C., Gu, Y. Q., Fu, D. L., \& Gill, B. S. (2013).

Sequence organization and evolutionary dynamics of Brachypodium-specific centromere retrotransposons. Retrieved from http://krex.ksu.edu

\section{Published Version Information}

Citation: Qi, L. L., Wu, J. J., Friebe, B., Qian, C., Gu, Y. Q., Fu, D. L., \& Gill, B. S. (2013). Sequence organization and evolutionary dynamics of Brachypodium-specific centromere retrotransposons. Chromosome Research, 21(5), 507-521.

Copyright: (C Springer Science+Business Media Dordrecht (Outside the USA) 2013

Digital Object Identifier (DOI): doi:10.1007/s10577-013-9378-4

Publisher's Link: http://link.springer.com/article/10.1007/s10577-013-9378-4

This item was retrieved from the K-State Research Exchange (K-REx), the institutional repository of Kansas State University. K-REx is available at http://krex.ksu.edu 
1 Sequence organization and evolutionary dynamics of Brachypodium-specific centromere

2 retrotransposons

3

4 L.L. $\mathrm{Qi}^{1^{* \dagger}}$, J.J Wu${ }^{2 *}$, B. Friebe ${ }^{3}$, C. Qian ${ }^{3}$, Y.Q. Gu ${ }^{4}$, D.L. Fu ${ }^{2}$, and B.S. Gill ${ }^{3}$ 5

$6 \quad$ IUSDA-ARS, Northern Crop Science Laboratory, 1605 Albrecht Blvd N, Fargo, ND

$7 \quad 58102-2765$ USA

$8 \quad{ }^{2}$ State Key laboratory of Crop Biology, College of Agronomy, Shandong Agricultural

9 University, 61 Daizong Street, Taian, Shandong, 271018, P. R. China

$10 \quad{ }^{3}$ Wheat Genetic Resources Center, Department of Plant Pathology, Kansas State

11 University, Manhattan, KS 66506-5502, USA

$12{ }^{4}$ USDA-ARS, Genomics and Gene Discovery Research Unit, Western Regional Research

13 Center, 800 Buchanan Street, Albany, CA, 94710 USA

$14 *$ These authors contributed equally to this work

$15{ }^{\dagger}$ For correspondence (phone +1 701239 1351; fax +1 701239 1346; email

16 lili.qi@ars.usda.gov)

17 
1 Abstract

2

3 Brachypodium distachyon is a wild annual grass belonging to the Pooideae, more closely

4 related to wheat, barley, and forage grasses than rice and maize. As an experimental

5 model, the completed genome sequence of $B$. distachyon provides a unique opportunity

6 to study centromere evolution during the speciation of grasses. Centromeric satellite

7 sequences have been identified in B. distachyon, but little is known about centromeric

8 retrotransposons in this species. In the present study, BAC-fluorescence in situ

9 hybridization was conducted in maize, rice, barley, wheat, and rye using $B$. distachyon

10 (Bd) centromere-specific BAC clones. Eight Bd centromeric BAC clones gave no

11 detectable FISH signals on the chromosomes of rice and maize, and three of them also

12 did not yield any FISH signals in barley, wheat, and rye. In addition, four of five

13 Triticeae centromeric BAC clones did not hybridize to the B. distachyon centromeres,

14 implying certain unique features of Brachypodium centromeres. Analysis of

15 Brachypodium centromeric BAC sequences identified a long terminal repeat (LTR)-

16 centromere retrotransposon of $B$. distachyon (CRBd1). This element was found in high

17 copy number accounting for $1.6 \%$ of the B. distachyon genome, and is enriched in

18 Brachypodium centromeric regions. CRBd1 accumulated in active centromeres, but was

19 lost from inactive ones. The LTR of CRBd1 appears to be specific to $B$. distachyon

20 centromeres. These results reveal different evolutionary events of this retrotransposon

21 family across grass species.

22

23 Introduction 
1 As chromosome landmarks, centromeres are responsible for kinetochore assembly that

2 links chromosome to microtubule spindle, and thereby enabling the faithful segregation

3 of sister chromatids during cell division. Extensive tracts of tandem repeats (centromeric

4 satellites) interrupted by various retrotransposons are common structural features of

5 centromeres (Copenhaver et al. 1999; Kumekawa et al. 1999, 2001; Jiang et al. 2003;

6 Zhang Y et al. 2004; Lamb et al. 2008). Satellite DNA and centromeric retrotransposons

7 (CR) are the most abundant DNA elements found in plant centromeres and are associated

8 with $\mathrm{CENH} 3$, a centromere-specific histone $\mathrm{H} 3$ present in nucleosomes of active

9 centromeres (Jiang et al. 1996; Miller et al. 1998; Presting et al. 1998; Cheng et al. 2002;

10 Zhong et al. 2002; Nagaki et al. 2003b, 2004).

12 Centromeric satellite DNA sequences have been isolated from several plant species,

13 including Arabidopsis (Round et al. 1997), maize (Ananiev et al. 1998), sorghum (Miller

14 et al. 1998), rice (Cheng et al. 2002; Zhang Y et al. 2004; Lee et al. 2005), Medicago

15 truncatual (Kulikova et al. 2004), Brassica (Lim et al. 2007), Brachypodium (2010), and

16 soybean (Tek et al. 2010). Although the repeat length, ranging in size from $155 \mathrm{bp}$ (rice)

17 to $180 \mathrm{bp}$ (Arabidopsis), is similar between taxa, their sequences are largely species-

18 specific and highly divergent even between closely related species (Lee et al. 2005). In

19 contrast to the centromeres of most plant species where functional centromeres are

20 mainly composed of large arrays of centromere satellite repeats and $C R$ elements (Jiang

21 et al. 2003), wheat centromeres lack tandem satellite repeats of megabase size and are

22 dominated by centromeric retrotransposons (Liu et al. 2008; Li et al. 2013). 
1 Unlike centromeric satellites, the $C R$ family in grass species is highly conserved. Two

2 highly conserved $C R$ sequences, CCS1 and pSau3A9, which are parts of Ty3/gypsy-type

3 retrotransposons, were first found to localize at the centromeres of most cereal species

4 that have been investigated (Aragon-Alcaide et al.1996; Jiang et al 1996, Miller et al.

5 1998; Presting et al. 1998). CRR (CR of rice) and CRM (CR of maize) are the most

6 intensively studied CR elements among plant species (Dong et al. 1998; Presting et al.

7 1998; Cheng et al. 2002; Zhong et al. 2002; Nagaki et al. 2003a, 2005). Rice CRR1 is

8 homologous to maize $C R M 3, C R R 2$ to $C R M 2, C R R 3$ to CRM1, and CRR4 to CRM4,

9 which pre-date the divergence of maize and rice (Sharma and Presting 2008). Two

10 putative $C R$ families of soybean were also grouped to CRR and CRM lineage (Du et al.

112010 ) and the $C R$ elements, Beetle1and Beetle 2, found in beet are highly similar to the

12 CRs of rice, maize, and Barley (Weber and Schmidt 2009). The $C R$ elements isolated

13 from barley and wheat showed cross hybridization among cereal species (Hudakova et al.

14 2001; Zhang P et al. 2004). As few exceptions to the general $C R$ conservation of grasses,

15 species-specific $C R$ element was reported in rye (Francki 2001) and wild rice (Gao et al.

16 2009). A rye-specific $C R$, Bilby that is a Tyl-copia retrotransposon-like element, is

17 highly divergent from other known cereal $C R$ elements, and a lineage-specific $C R$

18 element was identified in Oryza brachyantha.

20 Brachypodium distachyon (hereafter referred to as Brachypodium) is a wild annual grass

21 belonging to the Pooideae, more closely related to wheat, barley, and forage grasses than

22 rice and maize. As an experimental model, the completed genome sequence of

23 Brachypodium provides an important reference for grass biology and centromere studies 
1 (The International Brachypodium Initiative, 2010). A 156 bp Brachypodium centromeric

2 repeat (Bd_CENT) was identified and is present on all the Brachypodium centromeres

3 (The International Brachypodium Initiative, 2010). The only completely assembled

4 centromere is $45 \mathrm{~kb}$ long on chromosome Bd5 and is composed of two Bd_CENT arrays

5 occasionally interspersed with large blocks of unknown LTR retrotransposons (The

6 International Brachypodium Initiative, 2010). Previous studies indicated that the gene

7 sequences in the centromeric and pericetromeric regions from rice and wheat were

8 conserved with those in the centromeric/pericentromeric regions of Brachypodium,

9 indicating that these genes pre-existed in the centromere regions before the divergence of

10 the grass species that occurred 50-70 MYA (Bolot et al. 2009; Qi et al. 2010). However,

1154 genes found within $300 \mathrm{~kb}$ of all five Brachypodium centromeres were non-collinear

12 with rice and sorghum, indicating some unique features of Brachypodium centromeres

13 after it diverged from rice and wheat (The International Brachypodium Initiative, 2010).

14 In order to study the evolution of Brachypodium centromeres, we conducted BAC-

15 fluorescence in situ hybridization in maize, rice, barley, wheat and rye using 19

16 Brachypodium centromere-specific BAC clones, and annotated in detail four of these

17 BAC clones. The results demonstrate that Brachypodium CR elements are highly

18 divergent from those of other grass species.

20 Materials and Methods

22 Materials 
1 Seeds of B. distachyon, an inbred, diploid line Bd21, were obtained from USDA-ARS,

2 Pacific West Area, Western Regional Research Center, Genomics and Gene Discovery,

3 Albany, CA, USA. Chinese Spring (CS) wheat (Triticum aestivum L.), Imperial rye

4 (Secale cerale L.), Betzes barley (Hordeum vulgare L.) were provided by the Wheat

5 Genetic Resources Center at Kansas State University, KS, USA. Nipponbare rice (Oryza

6 sativa L.), and B73 maize (Zea mays L.) were provided by Drs. Frank White and Harold

7 Trick at the Plant Pathology Department, Kansas State University, KS, USA.

9 Methods

11 Selection of Brachypodium putative centromeric BAC

13 Three centromere-specific clones, Hi10, pRCS1, and pAet6-09, were used in the present

14 study. Both Hi10 and pRCS1 are cereal-specific centromeric DNA sequences; Hi10 was

15 isolated from B. sylvaticum (Abbo et al. 1995), and pRCS1 was derived from rice (O.

16 sativa ssp. Indica cv. IR-BB21) (Dong et al. 1998). The clone pAet6-09 was isolated

17 from Ae. tauschii bacterial artificial chromosome (BAC) library and hybridized to the

18 centromeres of wheat, barley, rye, and maize, but not to rice (Zhang P et al. 2004). Hi10

19 and pRCS1 were used to screen one high-density filter containing 18,432 clones from

20 Brachypodium BAC library $(-4.5 \times$ coverage) (Huo et al. 2006). The BAC clones with

21 unambiguous positive hybridization signals were selected, digested with HindIII, and

22 hybridized again to the three clones, Hi10, pRCS1, and pAet6-09. The putative

23 centromeric BAC clones were selected as probes for further BAC-fluorescence in situ 
1 hybridization (FISH) experiments (Table 1). Five additional Brachypodium BAC clones,

2 which previously gave BAC-FISH signals at the centromeres of Brachypodium

3 chromosomes were also used in the present study (Table 1, Qi et al. 2010). These BAC

4 clones were anchored by wheat pericentromeric ESTs from homoeologous chromosome

5 groups 3, 4, and 6. The procedure for colony filter hybridization and southern

6 hybridization was described by Qi et al. (2009).

8 Selection of the centromeric BAC clones from wheat 3B, Aegilops speltoides, and

9 Aegilops tauschii BAC libraries

11 Two wheat centromeric BAC clones, 3B-100-L17 and 3B-40-L07, were obtained by

12 screening a wheat 3B BAC library (Šafár et al. 2004) using the pAet6-09 sequence as

13 probe (Qi et al. unpublished data, Table 1). These two clones are located on the ordered

14 BACs of contig 796 (Feuillet, personal communication). Later, 3B-100-L17 as a single

$15 \mathrm{BAC}$ was placed in the $3 \mathrm{~B}$ centromere along with 12 sequenced contigs in $3 \mathrm{~B}$

16 chromosome (Choulet et al. 2010). Both clones exclusively hybridized to the centromeres

17 of wheat chromosomes (Fig. 1a). Two Ae. speltoides centromeric BAC clones, 21E12

18 and $256 \mathrm{~K} 19$, and one Ae. tauschii centromeric BAC clone HD008H01 were identified

19 previously by Qi et al. (2009) (Table 1).

21 BAC-fluorescence in situ hybridization (BAC-FISH) 
1 Mitotic chromosome spreads for BAC-FISH were prepared from the root tips of

2 Brachypodium Bd21, CS wheat, Imperial rye, Betzes barley, Nipponbare rice, and B73

3 maize as described by Qi et al. (2010). BAC DNA was isolated using a Qiagen Plasmid

4 Midi Kit following the manufacture's instruction (Qiagen Valencia. Calif.). One

5 microgram of BAC DNA was labeled with fluorescein-12-dUTP (Enzo Life Science Inc,

6 Farmingdale, NY) using nick translation. The BAC-FISH was performed on metaphase

7 chromosomes as previously described (Qi et al. 2010). Slides were analyzed with an

8 epifluorescence Zeiss Axioplan 2 microscope. Images were captured using a SPOT 2.1

9 CCD (charge-coupled device) camera (Diagnostic Instruments) and processed with

10 Photoshop v5.5 (Adobe Systems).

12 BAC sequence annotation

14 Four BAC clones, DB069J23, DB088O14, DB042E22 and DH017G05, were end

15 sequenced and then were anchored onto the Brachypodium chromosomes. A 300-kb

16 continuous stretch of sequence extending from one BAC-end was used for annotation

17 analysis. Self alignment of each BAC was performed using NCBI bl2seq BLAST tool to

18 generate a first glance of its repetitive nature. The RepeatScout (Price et al. 2005) was

19 also used to identify de novo repeats. To find common sequences among these BACs,

20 they were also aligned with each other. Transposable elements were identified by a

21 combination of BLAST searches against the GenBank nonredundant database and the

22 Triticeae Repeat Sequence Database (TREP, http://wheat.pw.usda.gov/ITMI/Repeats/).

23 LTR-FINDER (Zhao and Wang, 2007) was used to predict full-length LTR 
1 retrotransposons with tRNA database of Brachypodium. The insertion time of

2 retrotransposons was calculated according to Ma and Bennetzen (2004). The frequency

3 and distribution of the repeat elements along the chromosomes was analyzed by

4 searching the Brachypodium genome assembly (http://www.brachypodium.org/) with

5 NCBI local BLAST tool kit version 2.2.11, and the e-value cut-off was set to 1e-10. The

6 NCBI database, PlantGDB, CerealsDB, barley (webblast.ipk-gatersleben.de/barley/) and

7 rice (http://rice.plantbiology.msu.edu/) whole genome sequences were BLASTN searched

8 to identify conserved sequences of Brachypodium repeats.

10 Results

12 Identification of Brachypodium-specific centromeric BACs

14 The B. distachyon BAC library $(-4.5 \times$ coverage $)$ was probed with Hi10 and

15 pRCS1clones. Of the 38 unambiguous positive BAC clones, 13 were selected by probe

16 Hi10 and 25 by pRCS1 (Table S1). The BAC clones were digested with restriction

17 enzyme HindIII and hybridized to the three centromeric DNA sequences, Hi10, pRCS1,

18 and pAet6-09. Positive Southern hybridization signals and ladder patterns were detected.

19 Average numbers of BAC fragments hybridizing to three clones were 6.7 (range from 0

20 to 15 ) for Hi10, 7.0 (1 to 16) for pAet6-09, and 2.0 (0 to 4) for pRCS1 (Table S1).

21 Fourteen BAC clones that gave intense hybridization signals were selected for further

22 BAC-FISH with chromosome complements of Brachypodium and rye (Table S1). 
1 FISH results of the selected BAC clones to Brachypodium chromosomes indicated that

$214 \mathrm{BAC}$ clones exclusively hybridized to the centromeric regions of all Brachypodium

3 chromosomes with very strong FISH signals (Table 2, Fig. 2d). Subsequently, these BAC

4 clones along with other five Brachypodium BAC clones, DH017G05, DH039C01,

5 DB069J23, DB042E22, and DB088O14, which previously showed FISH signals on the

6 centromeric regions of all the five Brachypodium chromosomes (Qi et al. 2010), were

7 FISH mapped on rye chromosomes. The FISH on rye chromosomes showed variable

8 signal intensities exclusively at the primary constructions (Table 2, Figs. $2 \mathrm{~b}$ and $3 \mathrm{c}$ ).

9 Based on signal intensity, these 19 BACs were divided into four groups: group I with

10 three BACs showed strong signals (Fig. 2b), group II with six BACs gave faint signals

11 (Fig. 3c), group III with seven BACs showed the very weak signals on the rye

12 centromeres when image was exposed longer than usually required for detecting the

13 corresponding signals on Brachypodium centromeres, and group IV with three BACs

14 showed no FISH signals (Fig. 1d). To identify Brachypodium-specific centromeric BAC

15 clones, eight BAC clones were selected, all of which except DH007B23, gave very strong

16 signals on Brachypodium centromeric regions, but yielded variable signal intensities on

17 those of rye (Table 2), and were used to hybridize to chromosome complements of wheat,

18 barley, rice, and maize.

20 Surprisingly, no detectable FISH signal of eight selected BAC clones was observed on

21 the chromosomes of rice and maize, indicating that canonical sequences of

22 Brachypodium CR elements appear to have disappeared in these two species (Figs. 2e, 2f,

23 3d, and 3f). Out of eight BAC clones, three: DH017G05, DB042E22, and DB088O14, 
1 with a similar result on rye, also did not hybridize to the chromosomes of wheat and

2 barley, indicating that the centromere-specific sequences present in these BACs are

3 sufficiently conserved only in Brachypodium (Table 2, Fig. 1c and d). The remaining five

4 BAC clones showed variation in the intensity of the FISH signals in wheat, rye, and

5 barley. BAC DH021M4 had very strong FISH signals on the centromeres of

6 Brachypodium chromosomes, as well as in rye, wheat and barley. The FISH signal

7 intensity of BAC clones: DH010C12 and DH029E4, was similar in rye and wheat, but

8 lower in barley (Fig. 2a-c). BAC clones, DH008A23 and DH007B23, gave a weak

9 centromeric FISH signals in rye and wheat, but no signals in barley (Fig. 3a-c).

10 BAC-FISH of Triticeae centromeric BAC clones to Brachypodium chromosomes

12 Five centromeric BAC clones from wheat, Ae. speltoides, and Ae. tauschii were analyzed

13 for their hybridization to the chromosomes of Brachypodium. Only the BAC clone, 3B-

14 40-L07 derived from the wheat 3B BAC library, showed FISH signals on the centromeres

15 of Brachypodium chromosomes. Another 3B BAC clone, 3B-100-L17 residing at the

16 centromere of 3B chromosome, did not give any FISH signals on the Brachypodium

17 chromosomes (Fig. 1b, Table 3). Neither the two BAC clones from Ae. speltoides nor the

18 one from Ae. tauschii produced any FISH signals in Brachypodium, indicating that the

19 centromeric repeats in Triticeae have diverged from those in Brachypodium

21 Sequence organization of Brachypodium-specific centromeric BAC clones

23 Common repeats in the four Brachypodium BACs 
2 Sequence annotation was performed in four Brachypodium BAC clones, DH017G05,

3 DB069J23, DB042E22, and DB088O14. Because these BACs produced strong signals

4 only on Brachypodium centromeres in FISH experiments, they were all tested for the

5 presence of the 156 bp centromeric satellite repeat Bd_CENT (The International

6 Brachypodium Initiative, 2010) and found to be negative. The self alignments revealed

7 that DB069J23 was highly repetitive, and multiple copies of repeats were scattered in a

$8225 \mathrm{~kb}$ region (Fig. S1). Further comparison indicated that this repetitive region in

9 DB069J23 was also present in the other three BACs with variable copies. Using

10 RepeatScout program, a total of 26 repeat elements ( $>4$ copies) were identified in

11 DB069J23, and nine of them were repeated more than 10 times. The most abundant

12 repeats could be assembled into two contigs with $>80 \%$ sequence similarity, indicating

13 they belong to two repeat elements. Based on the Blastn searches against DB069J23 and

14 the Brachypodium whole genome sequence, these two repetitive contigs were represented

15 by two fragments in DB069J23, designated as RM-1 (DB069J23:107658-109770; 2113

16 bp) and RM-2 (DB069J23:271259-271757; 499 bp). In DB069J23, RM-1 fragment had

1746 copies with a total accumulative length of $49.3 \mathrm{~kb}$ and RM-2 had 24 copies with an

18 accumulative length of $9.6 \mathrm{~kb}$ (e-value $<1 \mathrm{e}-10)$. The conserved sequences of RM-1 in

19 DB088O14, DB042E22 and DH017G05 were 12.8, 2.4 and $9.8 \mathrm{~kb}$, respectively. As for

$20 \mathrm{RM}-2$, that was $3.7,1.5$ and $2.4 \mathrm{~kb}$, respectively.

22 RM-1 and RM-2 are a part of a single LTR specific to Brachypodium 
1 Detailed analysis of the Brachypodium genomic regions containing RM-1 and RM-2

2 revealed that these two repeats were parts of the LTR of one Gypsy retrotransposon found

3 in BAC DB088O14, designated as CRBd1 (Centromeric Retrotransposon of $B$.

4 distachyon, GeneBank \# KF040483) (Fig. 4a). RM-1 and RM-2 were located

5 immediately at the 3' and 5' end of the LTR, respectively. The complete LTR was about

$63.3 \mathrm{~kb}$ in length, and between the RM-1 and RM-2 was a region with high GC content

7 ( 70\%). Eight full length copies of CRBd1 were identified in the Brachypodium genome,

8 with size ranging from $12.5 \mathrm{~kb}$ to $12.8 \mathrm{~kb}$ (Supplementary file 1), and five of them were

9 located less than $3 \mathrm{Mb}$ from the centromeres or chromosome fusion points (Fig. 5, Table

10 S2). The insertion time of the eight full length CRBd1 was estimated to be in the range of

110.01 to 1.34 million years ago (Mya). Target site duplications (TSD) were found in 7 of

12 them. In the internal region $(\sim 6.2 \mathrm{~kb})$ between two LTRs, there were one Zinc knuckle

13 domain (pfam: zf-CCHC) and one chromatin organization modifier domain (pfam:

14 Chromo), besides feature proteins present in a typical LTR retrotransposable element

15 such as retrotransposase (Fig. 4a). Using the chromodomain identified in CRBd1as query

16 sequence, a total of 420 copies (e-value $<1 \mathrm{e}-5$ ) were identified in whole Brachypodium

17 genome. The distribution patterns of chromodomain are well consistent with that of

18 CRBd1 which is enriched in centromere regions (Fig. 5).

20 No full length element of CRBd1was identified in the four Brachypodium BACs. In BAC

21 DB088O14, two truncated and one fragmented elements, and one partial LTR and one

22 solo LTR were clustered in a $65.7 \mathrm{~kb}$ region in a different retrotransposon (Fig. $4 \mathrm{~b}$ ). The

23 CRBd1 homologous sequences occupied a total of $44.6 \mathrm{~kb}(67.9 \%)$ of this region. In 
1 comparison, CRBd1 element was more abundant in DB069J23 than in DB088O14 (Table

2 5), and the total length of homologous region was $101.2 \mathrm{~kb}$. More copies of the LTR than

3 the internal region of CRBd1 were present in DB069J23 (Fig. 4c), and 6 solo LTRs with

$4 \quad$ TSD were identified.

6 By searching the Brachypodium genome assembly with e-value of 1e-10, CRBd1 totally

7 occupied $4.41 \mathrm{Mb}$ in length and constituted $1.6 \%$ of the whole genome. Consistent with

8 the distribution pattern in DB069J23 (Fig.4c), the LTR of the CRBd1 was much more

9 abundant than the internal region, and many solo LTRs could be identified in the

10 Brachypodium genome (data not shown). The LTR of CRBd1 was obviously enriched in

11 the centromeric regions or Bd_CENT containing regions (Fig. 5). The top three most

12 abundant regions included the centromere of $\mathrm{Bd}$ chromosome 1, and two chromosome

13 fusion points (The International Brachypodium Initiative, 2010) on the long arm of Bd

14 chromosome 2 and the short arm of Bd chromosome 3. The total length of the sequences

15 homologous to the LTR is $2.76 \mathrm{Mb}$ in the Brachypodium genome.

17 Based on the sequence comparison to other grass species, the LTR of CRBd1 was

18 specific to Brachypodium. Only few sequences were found in wheat and barley with

19 limited conservation to small sections of the LTR. Given the genome coverage of the

20 current Triticeae datasets, the copy number of the homologous sequence should be very

21 low in wheat or barley. No conserved LTR sequence was found in rice, maize, sorghum

22 and rye. However, in these species, retrotransposons could be found that had about $70 \%$

23 DNA sequence identity to the internal region of $C R B d 1$, and the retrotransposons also 
1 had the conserved zf-CCHC and Chromo domains. Furthermore, the boundary sequences

2 (10-15bp) of the LTRs were conserved among the cereal species (Fig. 6).

3 Other retrotransposons in the four Brachypodium BACs

4

5 Besides CRBd1, another four retrotransposons were identified in at least one BAC (Table

6 4). CRBd2 (GeneBank \# KF040484, Fig. 4b) was identified in DB088O14 as a full length

7 Gypsy retrotransposon that showed $73 \%$ DNA sequence similarity to the rice centromeric

8 retrotransposon CRR3 (GenBank \# DQ458292). One full length CRBd2 and one solo

9 LTR were found in DB069J23 and DH017G05, respectively. The distribution of CRBd2

10 was also associated with centromeric regions or Bd_CENT containing regions (data not

11 shown). Its low content in the Brachypodium genome (263.7kb, 0.097\%) indicates that

12 CRBd2 was not highly repetitive (Table 4). Other three common retrotransposons which

13 we term 'retrotransposon element of B. distachyon' (REBd) including two Gypsy

14 retrotransposons, REBd1 (GeneBank \# KF0404850) and REBd2 (GeneBank \#

15 KF040486), and one Copia element REBd3 (GeneBank \# KF040487), were found in

16 DB088O14, DB069J23, and DH017G05, respectively (Table 4). These retrotransposons

17 were randomly distributed along the chromosomes without any obvious association with

18 centromeric regions.

20 In DB088O14, we observed the amplification of CRBd1 in the internal region of REBd1

21 element (Fig. 4b). After at least two rounds of insertion and deletion, one CRBd1 cluster

22 formed contained three truncated CRBd1 and two solo LTRs. Based on a substitution rate

23 of $1.3 \times 10^{-8}$ per site per year, the REBd1 containing the CRBd1cluster was originally 
1 inserted in between the genes Bradi3g44470 and Bradi3g44480 about 2.71 million years

2 ago (MYA). Another REBd1 retrotransposon at the 3'end of BAC DB088O14 was

3 inserted 3.27 MYA. In comparison, the REBd3 was a young retrotransposon inserted 0.23

4 MYA and another homolog REBd3 in DB042E22 was inserted 0.03 MYA with only one

5 nucleotide substitution between the two LTRs (1328 bp).

6

7 Discussion

9 Brachypodium centromeres, similar to cereal centromeres (rice, maize, and sorghum),

10 mainly consist of centromeric satellite sequences and retrotransposons (The International

11 Brachypodium Initiative 2010; Wen et al. 2012). Centromeric satellite sequences have

12 evolved and diverged rapidly and are largely species-specific, whereas centromere

13 retrotransposons (CR) appear to evolve more slowly (Round et al. 1997; Ananiev et al.

14 1998; Copenhaver et al. 1999; Henikoff et al. 2001; Cheng et al. 2002; Jin et al. 2004,

15 2005; Hall et al. 2003; Lee et al. 2005; Tek et al 2010). In the cereal species, CRRs in

16 rice, CRMs in maize, CRWs and Quinta in wheat, and Cereba in barley are highly

17 conserved across related genomes and over long evolutionary periods (Dong et al. 1998;

18 Miller et al. 1998; Presting et al. 1998; Hudakova et al. 2001; Zhang P et al. 2004; Liu et

19 al. 2008; Sharma and Presting 2008; Li et al. 2013). However, it was surprising to

20 observe that eight selected Brachypodium centromeric-BAC clones did not hybridize to

21 any centromeres of rice and maize. In addition, three of them also did not hybridize to the

22 centromeres of rye, wheat, and barley (Table 2). 
1 Sequence annotation of the four BACs revealed that two repetitive elements, RM-1 and

2 RM-2, were abundant in the Brachypodium genome, and belong to parts of the LTR of a

3 truncated gypsy retrotransposon, CRBd1, derived from BAC DB088O14 (Fig. 4). CRBd1

4 element was represented in all four BACs, and accounted for $4.4 \mathrm{Mb}(1.6 \%)$ of the $B$.

5 distachyon genome (Table 4). The LTR of CRBd1 harboring the RM-1 and RM-2 is

6 enriched in Brachypodium centromeric regions (Fig. 5), and is appeared to be a

7 Brachypodium specific sequence. Although LTRs usually diverge faster than the other

8 parts of the retrotransposons, highly conserved DNA motifs were found in the LTRs of

9 the $C R$ elements from rice, maize, and barley (Nagaki et al. 2003a). However, our results

10 indicate that the 3'end LTR of CRBd1 is significantly diverged in the other grass

11 genomes tested and had undergone rapid amplification in the regions of the currently

12 active centromeres during evolution of B. distachyon centromeres.

14 Comparative sequence analysis between Brachypodium, wheat, rice, and sorghum

15 revealed nested insertions of entire chromosomes into centromeric regions during the

16 evolution of five Brachypodium chromosomes from a 12-chromosome ancestor of all

17 grasses (The International Brachypodium Initiative 2010; Qi et al. 2010). Three of four

18 BACs analyzed, DH017G05, DB042E22, and DB088O14, were located at inactive

19 centromeres of Bd chromosomes 2 and 3, and both DH017G05 and DB042E22 are in the

20 fusion points of these chromosomes, indicating that these BAC clones were originally

21 located at the centromeric regions of ancestral chromosomes (Fig. 5). However, all these

22 BAC clones do not contain Brachypodium centromere satellite repeat, Bd_CENT. FISH

23 results showed that they landed to the active centromeres of Brachypodium, and none 
1 yielded FISH signals at their original positions. These results imply that the accumulation

2 of the $C R$ elements originally present in these BACs have preferentially occurred in the

3 regions of the currently active centromeres. It is also evident that the $C R$ element of

$4 \quad$ CRBd1 is more abundant in BAC DB069J23, which is located at the active centromere

5 region of Bd chromosome 4 (Fig. 5). The conserved sequence of CRBd1 were $101.2 \mathrm{~kb}$ in

6 length in DB069J23 compared to $44.6 \mathrm{~kb}$ in DB088O14, $20.8 \mathrm{~kb}$ in DH017G05, and 7.5

$7 \mathrm{~kb}$ in DB042E22 (Table 4). These results support the hypothesis that redundant

8 centromeres in Brachypodium chromosomes became inactive by the loss of centromeric

9 retrotransposons and rapid turnover of centromere-specific satellites (Qi et al. 2010). In

10 other words, the Brachypodium active centromeres maintain centromere satellite repeats

11 and accumulate $C R$ elements as a result of centromere drive (Ma et al. 2007; Wu et al.

12 2009). Only eight full length retrotransposons of CRBd1 were found in the Brachypodium

13 genome, and many solo-LTR of CRBd1 are present in the four BACs analyzed and in the

14 Brachypodium genome, revealing that CRBd1 is an ancient centromeric retrotransposon.

16 Rice and Brachypodium diverged approximately 40-54 MYA, while Brachypodium and

17 wheat diverged approximately 30 MYA (The International Brachypodium Initiative

18 2010). Although their genomes vary in size and basic chromosome numbers, gene

19 content and gene order has been largely conserved. The conserved genes were also

20 reported to be present in the centromere regions of rice, wheat, and Brachypodium, which

21 share the syntenic blocks among several sets of homologous centromeres (Qi et al. 2010).

22 However, the Brachypodium CR elements appear to be highly divergent from other grass

23 species, especially from rice and maize. Except three BAC clones mentioned above, five 
1 other Brachypodium centromeric BAC clones also did not yield any FISH signals in rice

2 and maize. These BAC clones were obtained by screening Brachypodium BAC library

3 using Hi10 as probe (Table 2). Hi10 was isolated from B. sylvaticum, a species diverged

4 from B. distachyon approximately 1.7-2.0 MYA (Buchmann et al. 2012), and contains

5 CCS1 sequence belonging to a cereal centromeric retrotransposon (Abbo et al. 1995;

6 Aragon-Alcaide et al. 1996). Wen et al. (2012) also reported that CCS1 failed to label $B$.

7 distachyon centromeres and its homologous sequences are comparatively less abundant in

8 the B. distachyon genome. In addition, all five Triticeae centromeric BAC clones used in

9 the present study, except one, 3B-40-L07, did not yield any FISH signals in the

10 Brachypodium centromeres (Table 3) (Qi et al. 2009, 2010). Among them, the 3B BAC

11 clone, 3B-100-L17, is a known 3B centromeric BAC placed in the centromere of 3B

12 chromosome by megabase sequencing analysis, which is highly collinear to the

13 centromere of rice chromosome 1 (Choulet et al. 2010). An extensive comparison of

14 centromeric sequences and distribution of $C R$ elements among rice, maize, wheat, and

15 Brachypodium might be needed for a complete understanding of the molecular and

16 evolutionary mechanisms underlying the conserved function of centromeres in cereal 17 species.

19 Acknowledgments

21 We thank Drs Zhao Liu and Gerald Seiler for critical review of the manuscript. This

22 research was supported by a special USDA-NIFA grant to the Wheat Genetic Resources

23 Center, Kansas State University, USA, and fund for excellent young scholar of Shandong 
1 Province of China (BS2011SW027). 
References

Abbo S, Dunford RP, Foote T, Reader SM, Flavell RB, Moore G (1995) Organization of retroelement and stem-loop repeat families in the genomes and nuclei of cereals. Chromosome Res 3:5-15

Ananiev EV, Phillips RL, Rines HW (1998) Chromosome-specific molecular organization of maize (Zea mays L.) centromeric regions. Proc Natl Acad Sci USA 95:13073-13078

Aragón-Alcaide L, Miller T, Schwatzacher T, Reader S, Moore G (1996) A cereal centromeric sequence. Chromosoma 105:261-268

Bolot S, Abrouk M, Masood-Quraishi U, Stein N, Messing J, Feuillet C, Salse J (2009) The 'inner circle' of the cereal genomes. Curr Opin Plant Bio 12:119-125

Buchmann JP, Matsumoto T, Stein N, Keller B, Wicker T (2012) Inter-species sequence comparison of Brachypodium reveals how transposon activity corrodes genome colinearity. Plant J 71:550-56

Cheng Z, Dong F, Langdon T, Ouyang S, Buell CR Gu MH, Blattner FR, Jiang J (2002) Functional rice centromeres are marked by a satellite repeat and a centromerespecific retrotransposon. Plant Cell 14:1691-1704

Choulet F, Wicker T, Rustenholz C et al (2010) Megabase level sequencing reveals contrasted organization and evolution patterns of the wheat gene and transposable element spaces. Plant Cell 22:1686-1701

Copenhaver GP, Nickel K, Kuromori T, Benito MI, Kaul S et al (1999) Genetic definition and sequence analysis of Arabidopsis centromeres. Science 286:2468-2474.

Dong F, Miller T, Jacson SA, Wang GL, Ronald PC, Jinag J (1998) Rice (Oryza sativa) centromeric regions consist of complex DNA. Proc Natl Acad Sci USA 95:8135-8140

Du J, Z Tian Z, Hans CS, Laten HM, Cannon SB, Jackson SA, RC Shoemaker RC, Ma J (2010) Evolutionary conservation, diversity and specificity of LTRretrotransposons in flowering plants: insights from genome-wide analysis and multi-specific comparison. Plant J 63:584-598 
1 Francki, MG (2001) Identification of Bilby, a diverged centromeric Ty1-copia retrotransposon family from cereal rye (Secale cereale L.). Genome 44:266-274

3 Gao D, Gill N, Kim HR, Walling JG, Zhang W, Fan C, Yu Y, Ma J, SanMigue P, Jiang

$4 \quad \mathrm{~N}$, et al (2009) A lineage-specific centromere retrotransposon in Oryza

5 brachyantha. Plant J 60:820-831

6 Hall SE, Kettler G, Preuss D (2003) Centromere satellites from Arabidopsis populations:

7 Maintenance of conserved and variable domains. Genome Res. 13:195-205

8 Henikoff S, Ahmad K, Malik HS (2001) The centromere paradox: stable inheritance with 9 rapidly evolving DNA. Science 203:1098-1102

10 Hudakova S, Michalek W, Presting GG, Ten Hoopen R, Dos Santos K, Jasencakova Z, 11 Schubert I (2001) Sequence organization of barley centromeres. Nucleic Acids $12 \quad$ Res 29:5029-5035

13 Huo N, Gu YQ, Lazo GR, Vogel JP, Coleman-Derr D, Luo MC, Thilmony R, Garvin DF, Anderson OD (2006) Construction and characterization of two BAC libraries from Brachypodium distachyon, a new model for grass genomics. Genome 49:1099-1108

Jiang J, Nasuda S, Dong F, Scherrer CW, Woo SS, Wing RA, Gill BS, Ward DC (1996) A conserved repetitive DNA element located in the centromeres of cereal chromosomes. Proc Natl Acad Sci USA 93:14210-14213

Jiang J, Birchler JA, Parrott WA, Dawe RK (2003) A molecular view of plant centromeres. Trends Plant Sci 8:570-575

Jin WW, Lamb JC, Vega JM, Dawe RK, Birchler JA, Jiang J (2005) Molecular and functional dissection of the maize B chromosome centromere. Plant Cell 17:1412-1423

Jin WW, Melo JR, Nagaki K, Talbert PB, Henikoff S, Dawe RK, Jiang J (2004) Maize centromeres: organization and functional adaptation in the genetic background of oat. Plant Cell 16:571-581

Kulikova O, Geurts R, Lamine M et al (2004) Satellite repeats in the functional centromere and pericentromeric heterochromatin of Medicago truncatula. Chromosoma 113:276-283

Kumekawa N, Ohtsubo E, Ohtsubo H (1999) Identification and phylogenetic 
analysis of gypsy-type retrotransposons in the plant kingdom. Genes Genet Syst 74:299-307

Kumekawa N, Ohmido N, Fukui K, Ohtsubo E, Ohtsubo H (2001) A new gypsy-type retrotransposon, RIRE7: preferential insertion into the tandem repeat sequence TrsD in pericentromeric heterochromatin regions of rice chromosomes. Mol Genet Genomics 265:480-488

Lamb JC, Yu W, Han F, Birchler JA (2008) Plant centromeres. Genome Dyn 4:95-107

Lee HR, Zhang W, Langdon T, Jin WW, Yan H, Cheng Z, Jiang J (2005) Chromatin immunoprecipitation cloning reveals rapid evolutionary patterns of centromeric DNA in Oryza species. Proc Natl Acad Sci USA 102:11793-11798

Lim K-B, Yang T-J, Hwang Y-J et al (2007) Characterization of the centromere and pericentromere retrotransposons in Brassica rapa and their distribution in related Brassica species. Plant J 49:173-183

Li B, Choulet F, Heng Y et al (2013) Wheat centromeric retrotransposons: the new ones take a major role in centromeric structure. Plant J 73:952-965

Liu Z, Yue W, Li D et al (2008) Structure and dynamics of retrotransposons at wheat centromeres and pericentromeres. Chromosoma 117:445-456

Ma J, Bennetzen JL (2004) Rapid recent growth and divergence of rice nuclear genomes. Proc Natl Acad Sci USA 101:12404-12410

Ma J, Wing R, Bennetzen JL, Jackson SA (2007) Evolutionary history and positional shift of a rice centromere. Genetics 177:1217-1220

Miller JT, Dong F, Jackson SA, Song J, Jiang J (1998) Retrotransposon-related DNA sequences in the centromeres of grass chromosomes. Genetics 150:1615-1623

Nagaki K, Song J, Stupar RM et al (2003a) Molecular and cytological analyses of large tracks of centromeric DNA reveal the structure and evolutionary dynamics of maize centromeres. Genetics 163:759-770

Nagaki K, Talbert PB, Zhong CX, Dawe RK, Henikoff S, Jiang J (2003b) Chromatin immunoprecipitation reveals that the 180-bp satellite repeat is the key functional DNA element of Arabidopsis thaliana centromeres. Genetics 163:1221-1225 
1 Nagaki K, Cheng Z, Ouyang S, Talbert PB, Kim M, Jones KM, Henikoff S, Buell CR, Jiang J (2004) Sequencing of a rice centromere uncovers active genes. Nature Genet 36:138-145

4 Nagaki K, Neumann P, Zhang D, Ouyang S, Buell CR, Cheng Z, Jiang J (2005) Structure, divergence, and distribution of the CRR centromeric retrotransposon

Qi LL, Friebe B, Zhang P, Gill BS (2009) A molecular-cytogenetic method for locating genes to pericentromeric regions facilitates a genome-wide comparison of synteny between the centromeric regions of wheat and rice. Genetics 183:1235-1247

Qi LL, Friebe B, Wu J, Gu Y, Qian C, Gill BS (2010) The compact Brachypodium genome conserves centromeric regions of a common ancestor with wheat and rice. Funct Integr Genomics 10:477-492

Round EK, Flowers SK, Richards EJ (1997) Arabidopsis thaliana centromere regions: genetic map positions and repetitive DNA structure. Genome Res 91:1007-1019

Šafár̆ J, Bartoš J, Janda J, et al (2004) Dissecting large and complex genomes: flow sorting and BAC cloning of individual chromosomes from bread wheat. Plant $\mathrm{J}$ 39:960-968

Sharma A, Presting GG (2008) Centromeric retrotransposon lineages predate the maize/rice divergence and differ in abundance and activity. Mol Genet Genomics 279:133-147

Tek AL, Kashihara K, Murata M, Nagaki K (2010) Functional centromeres in soybean include two distinct tandem repeats and a retrotransposon. Chromosome Res 18:337-347

The International Brachypodium Initiative (2010) Genome sequencing and analysis of 
the model grass Brachypodium distachyon. Nuture 463:763-768

2 Weber B, Schmidt T (2009) Nested Ty3-gypsy retrotransposons of a single

3 Betaprocumbens centromere contain a putative chromodomain. Chromsome Res

$4 \quad 17: 379-396$

5 Wen R, Moore G, Shaw PJ (2012) Centromeres cluster de novo at the beginning of

6 meiosis in Brachypodium distachyon. PLoS One 7:e44681

7 Wu J, Fujisawa M, Tian Z et al (2009) Comparative analysis of complete orthologous

8 centromeres from two subspecies of rice reveals rapid variation of centromere

9 organization and structure. Plant J 60:805-819

10 Zhang P, Li WL, Fellers J, Friebe B, Gill BS (2004) BAC-FISH in wheat

11 identifies chromosome landmarks consisting of different types of transposable

12 elements. Chromosoma 112:288-299

13 Zhang Y, Huang Y, Zhang L et al (2004) Structural features of the rice chromosome 4

14 centromere. Nucleic Acids Res. 32:2023-2030

15 Zhao X, Wang H (2007) LTR_FINDER: an efficient tool for the prediction of full-length

16 LTR retrotransposons. Nucleic Acids Res 35 (Web Server issue): W265-W268

17 Zhong CX, Marshall JB, Topp C et al (2002) Centromeric retroelements and satellites

18 interact with maize kinetochore protein CENH3. Plant Cell 14:2825-2836 
Table 1 List of BAC clones selected for BAC-FISH

\begin{tabular}{lllll}
\hline Probed by & BAC clones & $\begin{array}{l}\text { Contigs or } \\
\text { chromosome }\end{array}$ & Classification & Reference \\
\hline Hi10 & DH007B23 & Ctg118 & Brachypodium BAC & This research \\
Hi10 & DH021M4 & Ctg271 & Brachypodium BAC & This research \\
Hi10 & DH008A23 & Ctg290 & Brachypodium BAC & This research \\
Hi10 & DH010C12 & Ctg42 & Brachypodium BAC & This research \\
Hi10 & DH029E4 & Ctg42 & Brachypodium BAC & This research \\
Hi10 & DH010J10 & Singleton & Brachypodium BAC & This research \\
Hi10 & DH010O24 & Singleton & Brachypodium BAC & This research \\
Hi10 & DH017123 & Singleton & Brachypodium BAC & This research \\
pRCS1 & DH054L6 & Singleton & Brachypodium BAC & This research \\
pRCS1 & DH064P10 & Singleton & Brachypodium BAC & This research \\
pRCS1 & DH070K6 & Singleton & Brachypodium BAC & This research \\
pRCS1 & DH078K1 & Singleton & Brachypodium BAC & This research \\
pRCS1 & DH085J19 & Singleton & Brachypodium BAC & This research \\
pRCS1 & DH086J9 & Singleton & Brachypodium BAC & This research \\
BG313557-3L ${ }^{\dagger}$ & DH017G05 & Bd 2 & Brachypodium BAC & Qi et al. 2010 \\
& DH039C01 & Bd 2 & Brachypodium BAC & Qi et al. 2010 \\
BE637507-4L ${ }^{\dagger}$ & DB069J23 & Bd 4 & Brachypodium BAC & Qi et al. 2010 \\
BE405809-6S ${ }^{\dagger}$ & DB042E22 & Bd 3 & Brachypodium BAC & Qi et al. 2010 \\
BE405195-6S ${ }^{\dagger}$ & DB088O14 & Bd 3 & Brachypodium BAC & Qi et al. 2010 \\
pAet6-09 & 3B-100-L17 & Ctg796 & Wheat 3B BAC & Qi unpublished data \\
& 3B-40-L07 & Ctg796 & Wheat 3B BAC & Qi unpublished data \\
BF202706-4DL & $21 E 12$ & NA & Ae. speltoides BAC & Qi et al. 2009 \\
& $256 K 19$ & NA & Ae. speltoides BAC & Qi et al. 2009 \\
BE497309-4DS & HD008H01 & Singleton & Ae. tauschii BAC & Qi et al. 2009 \\
\hline$\dagger$
\end{tabular}

$\dagger$ wheat pericentromeric EST. Brachypodium BAC clone was selected based on the sequence similarity to the wheat EST. 
Table 2 The results of BAC-fluorescence in situ hybridization (FISH) of Brachypodium BAC clones on the mitotic chromosome complements of Brachypodium, rye, wheat, barley, rice, and maize.

\begin{tabular}{|c|c|c|c|c|c|c|c|}
\hline \multirow[b]{2}{*}{ Probed by } & \multirow{2}{*}{$\begin{array}{l}\text { BAC } \\
\text { clones }\end{array}$} & \multicolumn{6}{|c|}{ BAC-FISH signal } \\
\hline & & B.d21 & Rye & wheat & Barley & Rice & Maize \\
\hline Hi10 & DH021M4 & ++++ & +++ & +++ & +++ & - & - \\
\hline Hi10 & DH029E4 & ++++ & +++ & +++ & ++ & - & - \\
\hline Hi10 & DH010C12 & ++++ & +++ & ++ & + & - & - \\
\hline Hi10 & DH007B23 & +++ & ++ & + & - & - & - \\
\hline Hi10 & DH008A23 & ++++ & ++ & + & - & - & - \\
\hline Hi10 & DH017I23 & +++ & ++ & NA & NA & NA & NA \\
\hline pRCS1 & DH054L6 & +++ & ++ & NA & NA & NA & NA \\
\hline pRCS1 & DH085J19 & ++++ & ++ & NA & NA & NA & NA \\
\hline pRCS1 & DH086J9 & ++++ & ++ & NA & NA & NA & NA \\
\hline Hi10 & DH010J10 & +++ & + & NA & NA & NA & NA \\
\hline Hi10 & DH010O24 & +++ & + & NA & NA & NA & NA \\
\hline pRCS1 & DH064P10 & ++++ & + & NA & NA & NA & NA \\
\hline pRCS1 & DH070K6 & ++++ & + & NA & NA & NA & NA \\
\hline pRCS1 & DH078K1 & ++++ & + & NA & NA & NA & NA \\
\hline BG313557-3L $\mathrm{L}^{\dagger}$ & DH039C01 & ++++ & + & NA & NA & NA & NA \\
\hline BE637507-4L ${ }^{\dagger}$ & DB069J23 & ++++ & + & NA & NA & NA & NA \\
\hline BG313557-3L $\mathrm{L}^{\dagger}$ & DH017G05 & ++++ & - & - & - & - & - \\
\hline BE405809-6S ${ }^{\dagger}$ & DB042E22 & ++++ & - & - & - & - & - \\
\hline BE405195-6S ${ }^{\dagger}$ & DB088014 & ++++ & - & - & - & - & - \\
\hline
\end{tabular}

- and + represent, respectively, the absence and presence of hybridization signals: ++++, very strong signal; +++, strong signal; ++, weak signal; +, very weak signal.

${ }^{\dagger}$ wheat pericentromeric EST. Brachypodium BAC clone was selected based on the sequence similarity to the wheat EST.

2 NA: not apply. 
1

2 Table 3 The results of BAC-fluorescence in situ hybridization (FISH) of Triticeae BAC clones on 3 the mitotic chromosome complement of wheat Chinese Spring (CS) and B. distachyon (B.d21)

\begin{tabular}{lcc}
\hline & \multicolumn{2}{c}{ BAC-FISH signal } \\
\cline { 2 - 3 } BAC clones & CS & B.d21 \\
\hline 3B-40-L07 & +++ & ++ \\
3B-100-L17 & +++ & - \\
21E12 & +++ & - \\
256K19 & +++ & - \\
HD008H01 & +++ & - \\
\hline
\end{tabular}

- and + represent, respectively, the absence and presence of hybridization signals: +++ , strong signal; ++, weak signal.

6

7 Table 4 Common LTR retrotransposons identified in the four Brachypodium BACs

\begin{tabular}{|c|c|c|c|c|c|c|c|c|}
\hline \multirow{2}{*}{ No. } & \multirow{2}{*}{ Name } & \multirow{2}{*}{ Family } & \multirow{2}{*}{ Structure } & \multicolumn{5}{|c|}{ Total length of conserved sequence $(\mathrm{kb})$} \\
\hline & & & & DB069J23 & DB088014 & DB042E22 & DH017G05 & $\begin{array}{c}\text { whole } \\
\text { genome }\end{array}$ \\
\hline 1 & $\begin{array}{c}C R B d 1 \\
(9.76 \mathrm{~kb})\end{array}$ & Gypsy & truncated & 101.2 & 44.6 & 7.5 & 20.8 & $4,410.6^{\dagger}$ \\
\hline 2 & $\begin{array}{c}C R B d 2 \\
(7.23 \mathrm{~kb})\end{array}$ & Gypsy & $\begin{array}{c}\text { Full length, } \\
\text { similar to rice } \\
\text { CRR3 }\end{array}$ & $\begin{array}{c}7.6 \\
\text { (Full } \\
\text { length) }\end{array}$ & $\begin{array}{c}7.2 \\
\text { (Full } \\
\text { length) }\end{array}$ & 0.3 & $\begin{array}{c}0.9 \\
\text { (solo LTR) }\end{array}$ & 263.7 \\
\hline 3 & $\begin{array}{c}R E B d 1 \\
(11.64 \mathrm{~kb})\end{array}$ & Gypsy & Full length & 2.2 & 22.2 & 11.3 & $\begin{array}{c}0.9 \\
\text { (solo LTR) }\end{array}$ & $2,011.1$ \\
\hline 4 & $\begin{array}{c}R E B d 2 \\
(7.29 \mathrm{~kb})\end{array}$ & Gypsy & $\begin{array}{c}\text { Internal } \\
\text { coding region }\end{array}$ & 15.1 & 0 & 12.4 & 11.9 & 4264.0 \\
\hline 5 & $\begin{array}{c}R E B d 3 \\
(8.03 \mathrm{~kb})\end{array}$ & Copia & Full length & 0 & 0 & $\begin{array}{c}8.0 \\
\text { (Full } \\
\text { length) } \\
\end{array}$ & $\begin{array}{c}8.0 \\
\text { (Full } \\
\text { length) } \\
\end{array}$ & 913.5 \\
\hline
\end{tabular}

8

$\dagger$ Of them, the total length of sequences conserved to the LTR region of CRBd1 was $2758.7 \mathrm{~kb}$. 
1

2 Table S1 Hybridization results of positive Brachypodium BACs with centromeric-specific 3 clones, Hi10, pAet6-09, and pRCS1

\begin{tabular}{|c|c|c|c|c|}
\hline \multirow[b]{2}{*}{ Probed by } & \multirow[b]{2}{*}{ Associated BAC } & \multicolumn{3}{|c|}{ No. fragments of BAC hybridizing to: } \\
\hline & & Hi10 & pAet6-09 & $\mathrm{pRCS} 1$ \\
\hline \multirow[t]{13}{*}{ Hi10 } & DH002F21 & 8 & 8 & 2 \\
\hline & DH007B23 ${ }^{\dagger}$ & 2 & 2 & 0 \\
\hline & DH007C24 & 7 & 7 & 1 \\
\hline & DH008A23 ${ }^{\dagger}$ & 8 & 8 & 3 \\
\hline & DH010C12 ${ }^{\dagger}$ & 6 & 7 & 1 \\
\hline & DH010J10 $0^{\dagger}$ & 10 & 10 & 1 \\
\hline & $\mathrm{DH} 010 \mathrm{O} 24^{\dagger}$ & 14 & 16 & 3 \\
\hline & DH026L22 & 4 & 2 & 2 \\
\hline & DH014I5 & 2 & 4 & 2 \\
\hline & DH017I $23^{\dagger}$ & 7 & 7 & 2 \\
\hline & $\mathrm{DH} 021 \mathrm{M} 4^{\dagger}$ & 2 & 3 & 1 \\
\hline & DH024H22 & 9 & 11 & 1 \\
\hline & DH029E $4^{\dagger}$ & 5 & 5 & 1 \\
\hline \multirow[t]{25}{*}{ pRCS1 } & DH003K1 & 3 & 5 & 1 \\
\hline & DH011N9 & 5 & 6 & 2 \\
\hline & DH014I7 & 7 & 9 & 2 \\
\hline & DH017C21 & 7 & 6 & 4 \\
\hline & DH027C19 & 0 & 1 & 2 \\
\hline & DH028M13 & 9 & 9 & 3 \\
\hline & DH030F13 & 4 & 2 & 2 \\
\hline & DH031H5 & 3 & 3 & 3 \\
\hline & DH032L2 & 3 & 3 & 2 \\
\hline & DH032J23 & 1 & 1 & 2 \\
\hline & DH039M8 & 9 & 9 & 3 \\
\hline & DH042I3 & 5 & 5 & 3 \\
\hline & DH054L6 ${ }^{\dagger}$ & 10 & 9 & 3 \\
\hline & DH056C10 & 5 & 5 & 2 \\
\hline & DH060A1 & 5 & 8 & 1 \\
\hline & DH062J15 & 6 & 7 & 2 \\
\hline & DH064P10 ${ }^{\dagger}$ & 11 & 12 & 2 \\
\hline & DH070K $6^{\dagger}$ & 10 & 10 & 2 \\
\hline & DH078K $1^{\dagger}$ & 12 & 12 & 4 \\
\hline & DH085J19 ${ }^{\dagger}$ & 15 & 13 & 2 \\
\hline & DH086J $9^{\dagger}$ & 14 & 13 & 4 \\
\hline & DH087M5 & 3 & 4 & 1 \\
\hline & DH089N24 & 9 & 9 & 1 \\
\hline & DH090B7 & 5 & 6 & 1 \\
\hline & DH090F5 & 8 & 8 & 3 \\
\hline
\end{tabular}

\footnotetext{
${ }^{\dagger}$ selected for BAC-FISH
}

4

5 
2 Table S2 Distribution of the full-length CRBd1 in B. distachyon genome

\begin{tabular}{|c|c|c|c|c|}
\hline $\begin{array}{l}\text { Chromosome } \\
\text { No. }\end{array}$ & $\begin{array}{l}\text { Position of Bd_CENT repeats } \\
\text { in centromere regions }\end{array}$ & $\begin{array}{l}\text { Position of Bd_CNET repeats } \\
\text { in chromosome fusion points }\end{array}$ & $\begin{array}{l}\text { Position of Bd_CNET repeats } \\
\text { outside of the centromeres }\end{array}$ & $\begin{array}{l}\text { Position of full length } C R B d 1 \\
\text { (Insertion time) }\end{array}$ \\
\hline 1 & $37.379-38.177 \mathrm{Mb}(1294)^{\dagger}$ & $\begin{array}{l}24.696-24.700 \mathrm{Mb}(27) \\
50.742-50.744 \mathrm{Mb}(13)\end{array}$ & $\begin{array}{l}23.017-23.020 \mathrm{Mb}(13) \\
30.402 \mathrm{Mb}(2) \\
36.856-36.866 \mathrm{Mb}(47) \\
40.922 \mathrm{Mb}(3)\end{array}$ & $\begin{array}{l}39.080-39.093 \mathrm{Mb}(0.14 \mathrm{Myr}) \\
70.916-70.929 \mathrm{Mb}(0.01 \mathrm{Myr})\end{array}$ \\
\hline 2 & 28.989-29.716 Mb (340) & $\begin{array}{l}12.733-12.735 \mathrm{Mb}(13) \\
40.087-40.088 \mathrm{Mb}(12)\end{array}$ & & 26.344-26.357 Mb (0.06Myr) \\
\hline 3 & 25.158-25.675 Mb (1607) & $11.136-11.153 \mathrm{Mb}(28)$ & $24.365-24.388 \mathrm{Mb}(53)$ & \\
\hline 4 & 20.641-21.023 Mb (1264) & 24.724-24.734 Mb (61) & & $\begin{array}{l}8.206-8.219 \mathrm{Mb}(0.02 \mathrm{Myr}) \\
22.075-22.088 \mathrm{Mb}(1.34 \mathrm{Myr}) \\
26.875-26.888 \mathrm{Mb}(0.01 \mathrm{Myr})\end{array}$ \\
\hline 5 & 7.608-7.731 Mb (194) & & $\begin{array}{l}\text { 7.293-7.314 Mb (14) } \\
8.103 \mathrm{Mb}(1)\end{array}$ & $\begin{array}{l}1.524-1.537 \mathrm{Mb}(0.12 \mathrm{Myr}) \\
9.032-9.045 \mathrm{Mb}(0.14 \mathrm{Myr})\end{array}$ \\
\hline
\end{tabular}

3

${ }^{\dagger}$ The numbers in parentheses represent the copy numbers of Bd_CENT 
1 Figure legends

2 Figure 1
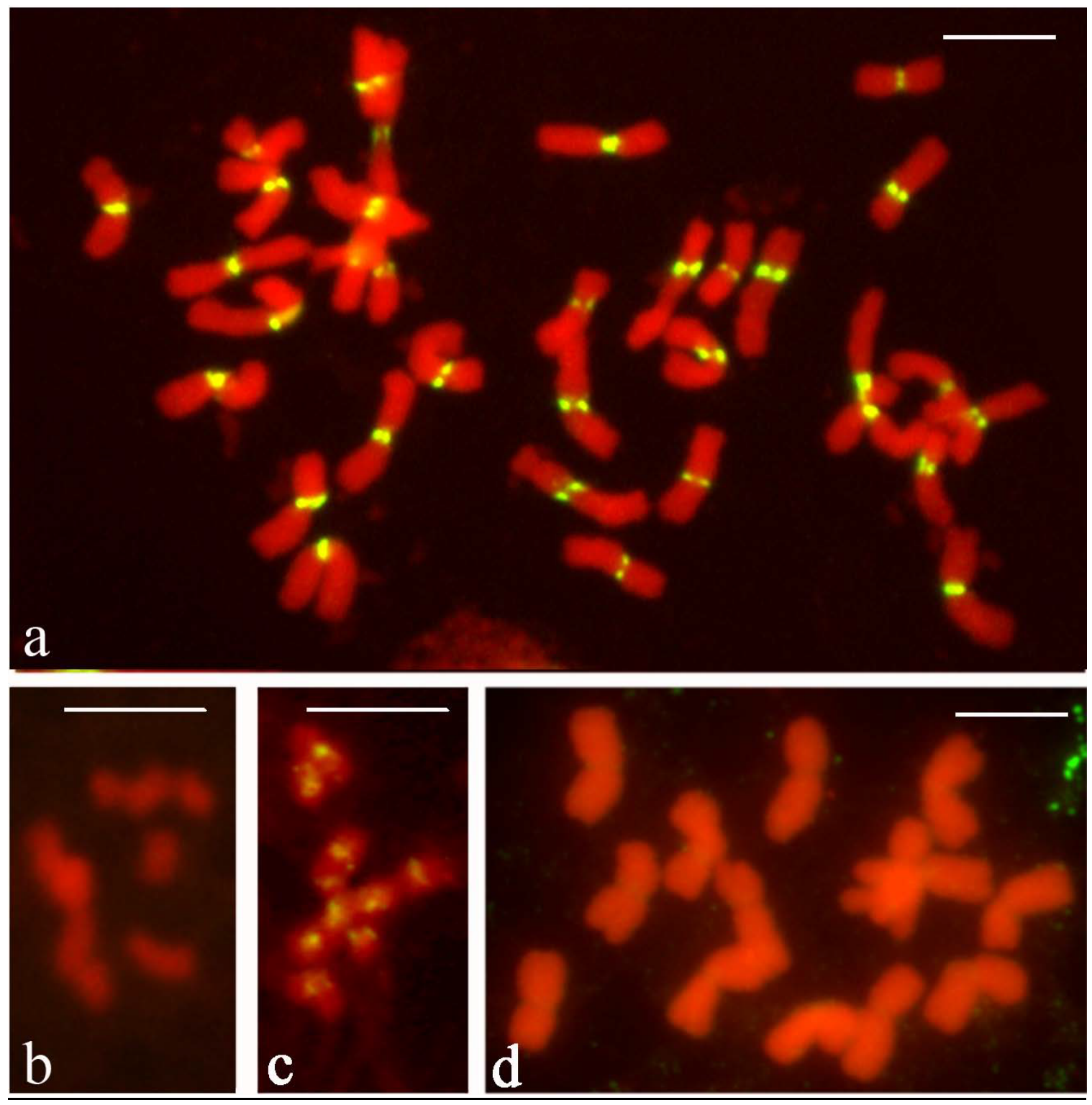

4 Fig. 1 Wheat 3B BAC clone 3B-100-L17 hybridized to mitotic chromosomes of wheat

5 (a) and Brachypodium (b). No FISH signal was observed in Brachypodium chromosomes

6 (b). Brachypodium BAC clone DB088014 hybridized to mitotic chromosomes of

7 Brachypodium (c) and rye (d). No FISH signal was observed in rye chromosomes (d), as

8 well as in wheat, barley, maize, and rice (data not shown). Scale bar is $5 \mu \mathrm{m}$. 
$\underline{\text { Figure } 2}$

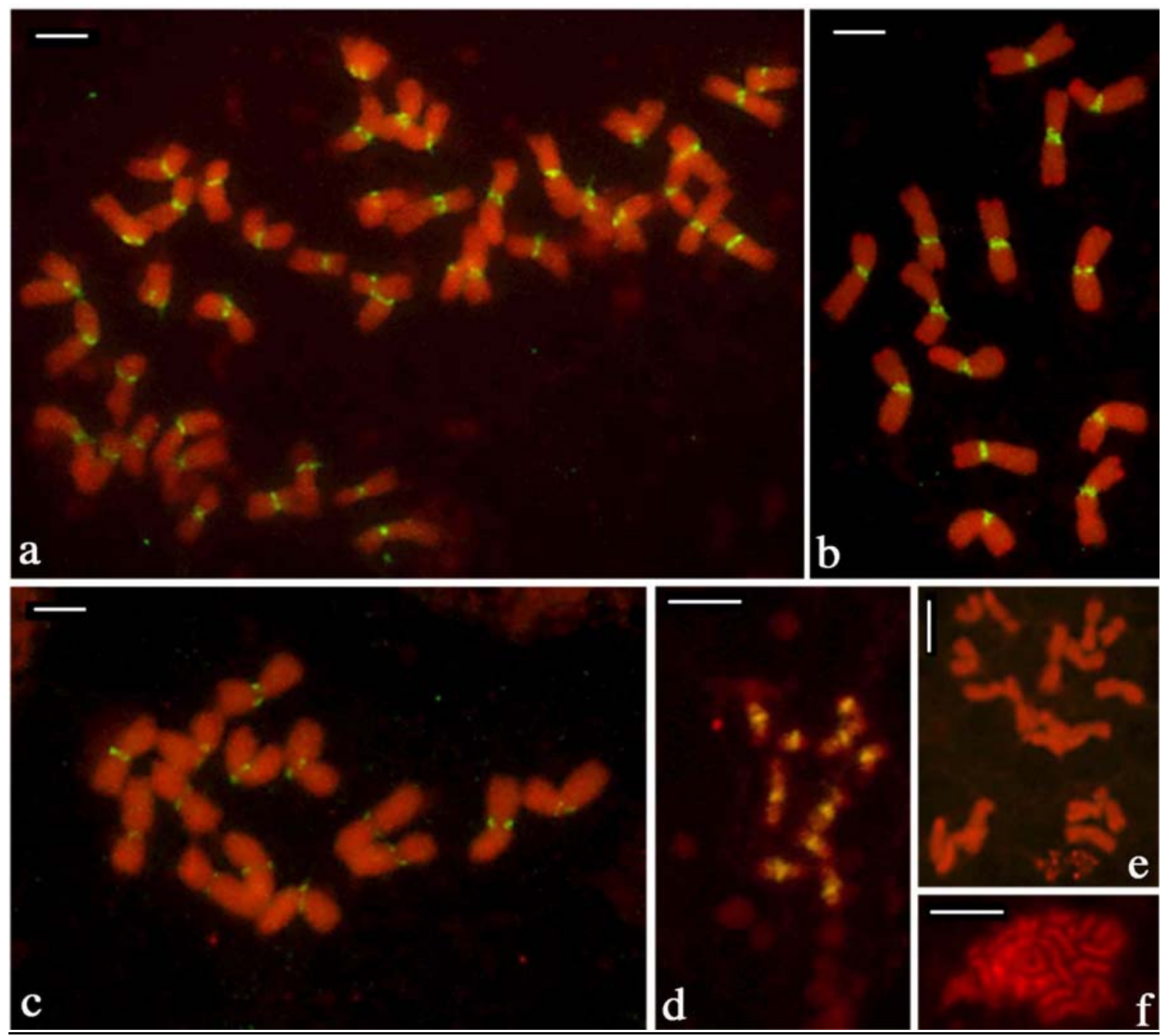

3 Fig. 2 Brachypodium BAC clone DH029E4 hybridized to mitotic chromosomes of wheat

4 (a), rye (b), barley (c), Brachypodium (d), Maize (e), and rice (f). No FISH signal was

5 observed in maize (e) and rice (f) chromosomes. Scale bar is $5 \mu \mathrm{m}$. 
$\underline{\text { Figure } 3}$
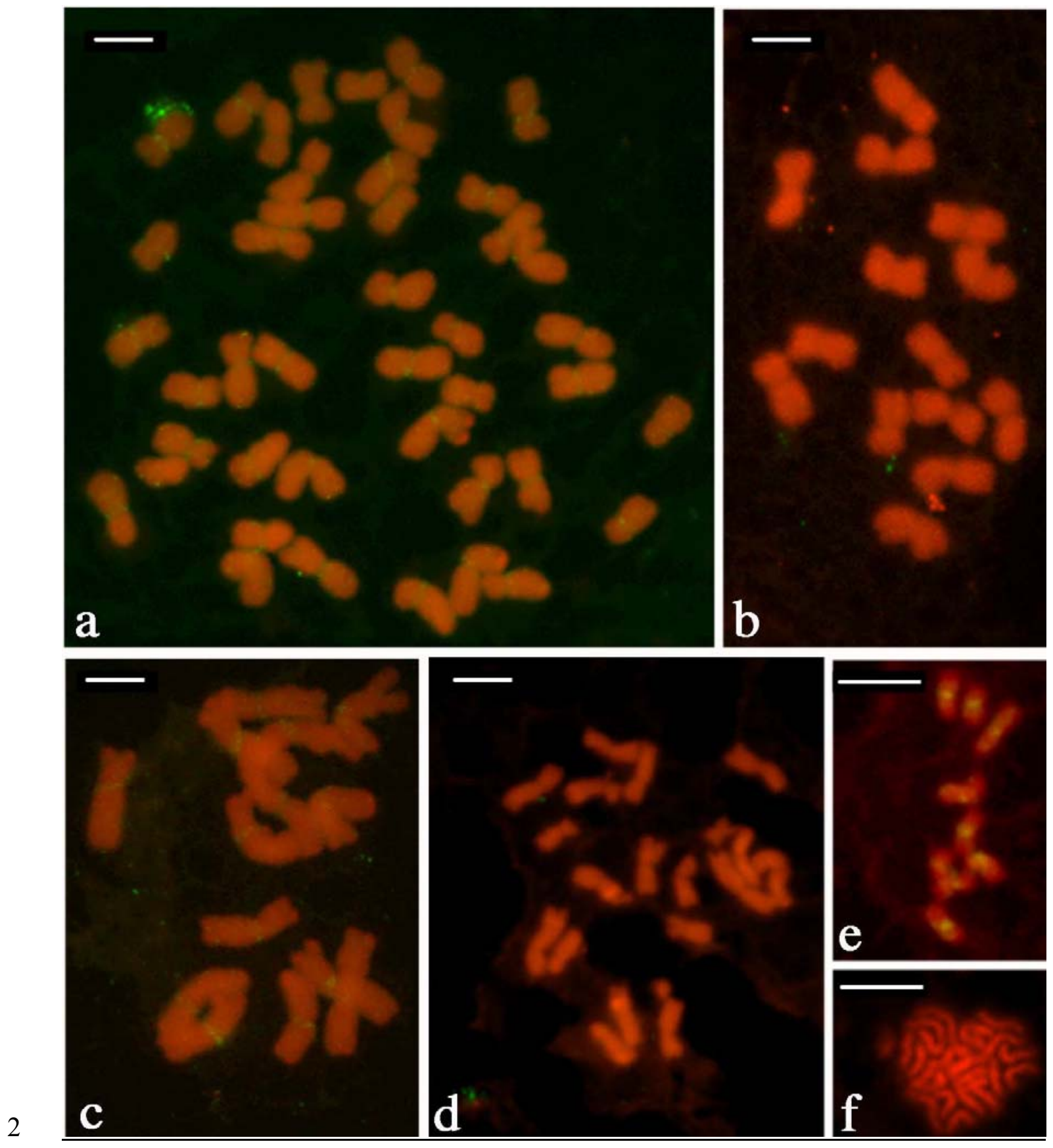

3 Fig. 3 Brachypodium BAC clone DH007B23 hybridized to mitotic chromosomes of

4 wheat (a), barley (b), rye (c), maize (d), Bd21 (e), and rice (f). No FISH signal was

5 observed in the chromosomes of barley (b), maize (d), and rice (f). Scale bar is $5 \mu \mathrm{m}$. 
$\underline{\text { Figure } 4}$

a)

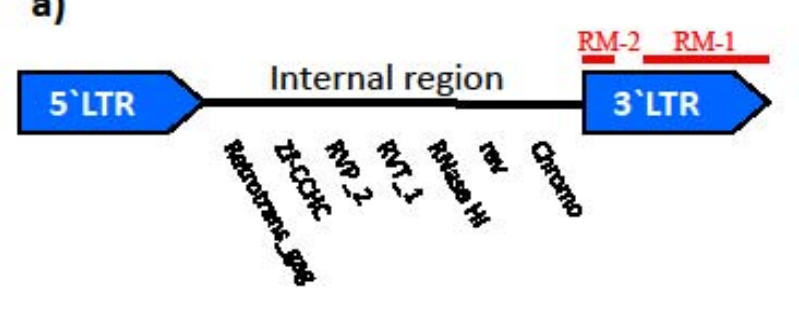

b)

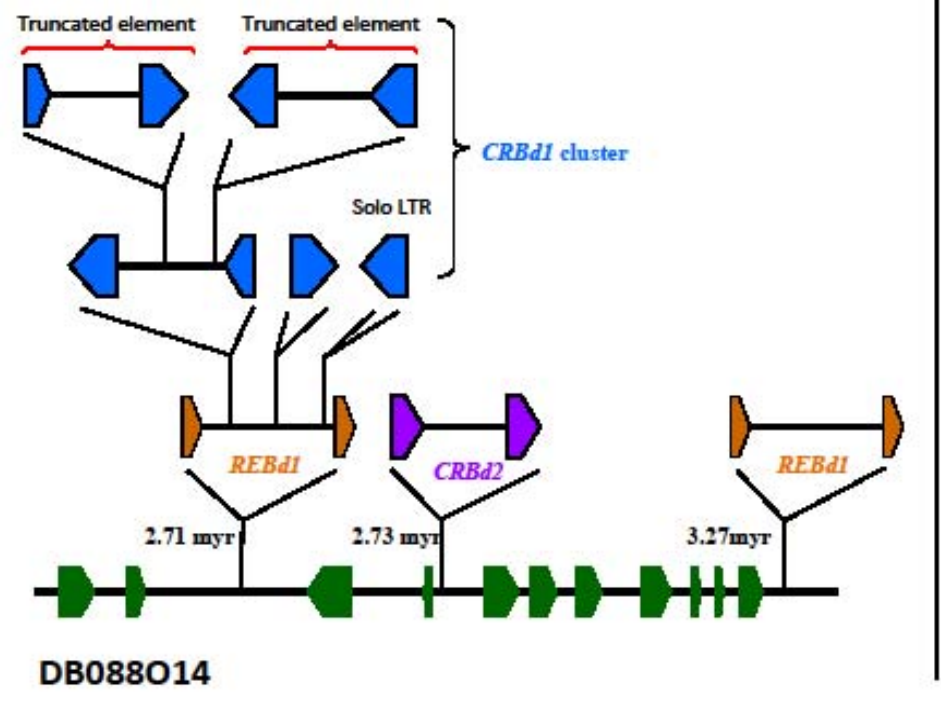

c) CRBd1

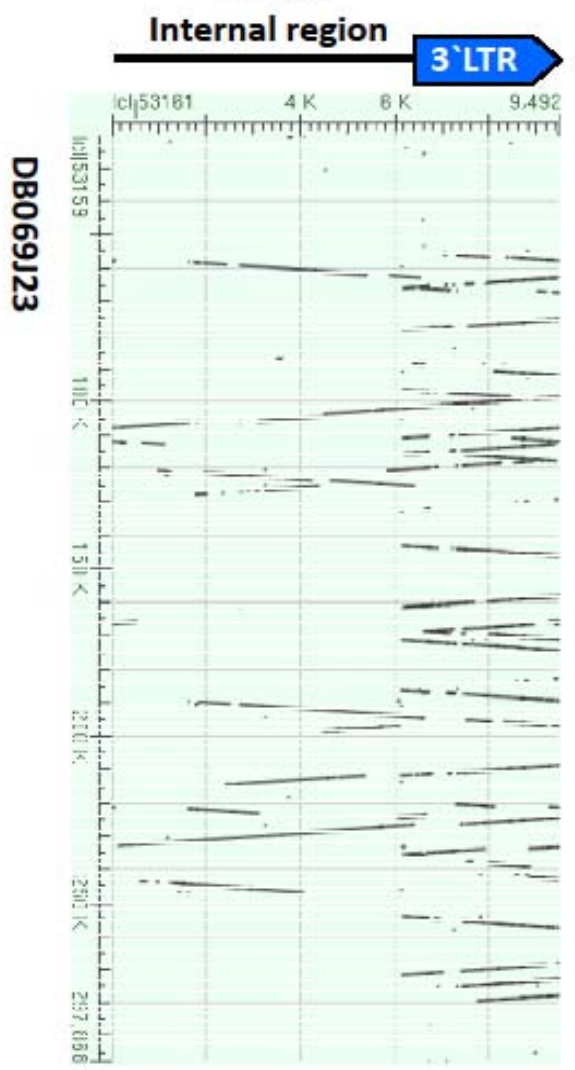

2

3

4 Fig. 4 The structure and distribution of the retrotransposon CRBd1. a) The full length

5 element of CRBd1 retrotransposon in Brachypodium was 12.5-12.8 kb in length with

6 LTRs of 3.1-3.3kb. The deduced coding sequence contains typical domains of

7 retrotransposon: gag protein (Retrotrans_gag), pol protein (RVP_2), reverse transcriptase

8 (RVT_1), RNase H1 and integrase (rev), as well as other two domains, the Zinc knuckle

9 domain (zf-CCHC) and Chromatin Organization Modifer domain (Chromo). The

10 Brachypodium specific repeats, RM-1 and RM-2 identified in DB069J23, were fragments

11 of the LTR region of CRBd1. b) Distribution of the retrotransposons in the BAC 
1 DB088O14. The green boxes represent the 11 gene models in the 200kb-region of

2 chromosome 3:46336326..46536325. Black lines flanked by two boxes indicate

3 retrotransposons, under which the names were labeled. Retrotransposons were inserted

4 into other retrotransposons or intergenic region. A CRBd1 cluster was noticed in this

5 BAC, including the truncated elements and solo-LTRs. The insertion time of full length

6 retrotransposons were calculated and labeled under the elements. c) The dot matrix view

7 of the alignment between BAC DB069J23 (Bd4: 22540676..22840675) and the

8 retrotransposon CRBd1(DB088O14:25723..35498), indicating the distribution of the

9 sequences with similarity to CRBd1 in this BAC. For simplicity, only the internal region

10 and the 3'LTR of CRBd1 were used for comparison.

11 


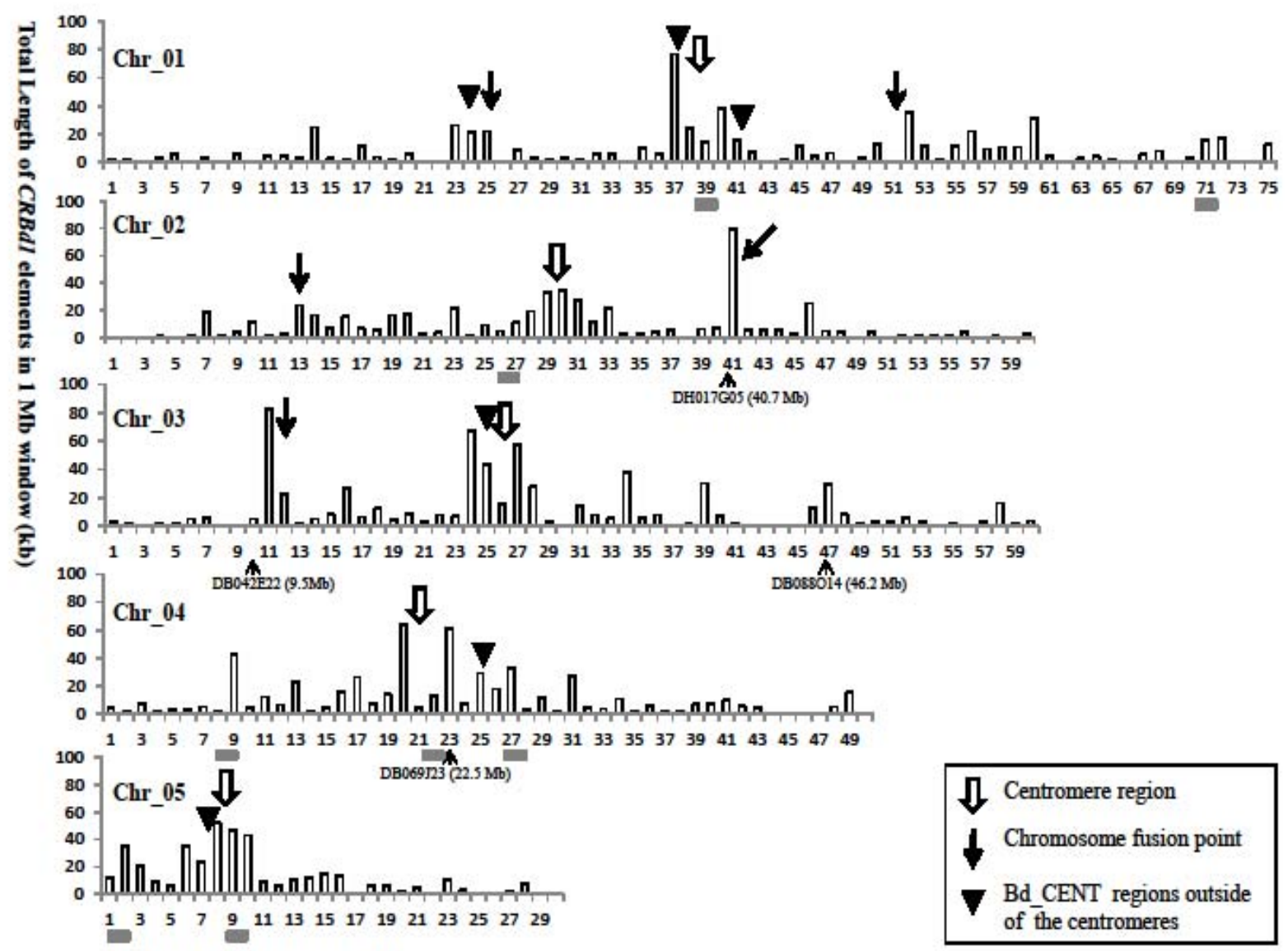

Fig. 5

4 Fig. 5 The distribution histograms of the LTR of CRBd1 on the Brachypodium

5 chromosomes. The total sequence length $(\mathrm{kb})$ of alignments in $1 \mathrm{Mb}$ window was plotted

6 along the chromosomes. The positions of centromeres, chromosome fusion points, and

7 Bd_CENT containing regions outside of the centromeres were marked. The arrows point

8 the positions of the four Brachypodium BACs, and the gray bars represent the positions

9 of the eight full-length CRBd1. 


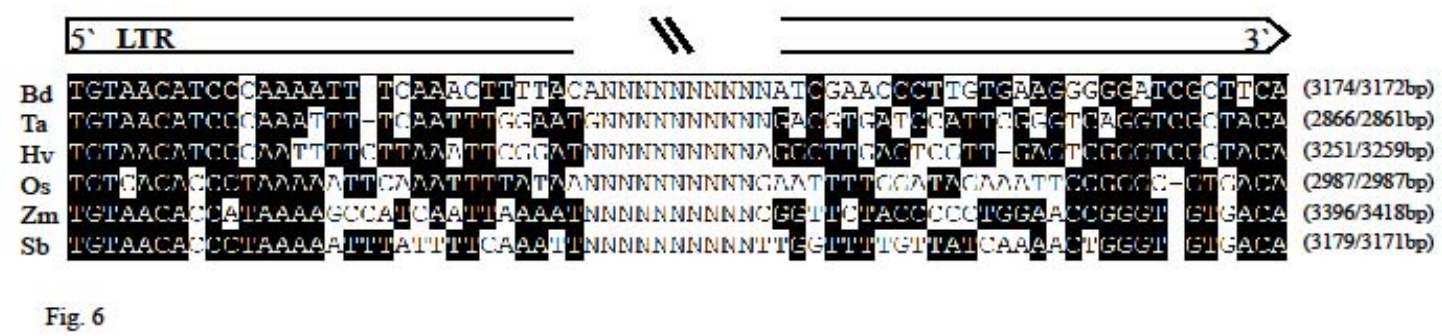

2

4 Fig. 6 Sequence alignment of the LTRs from different species. Full length

5 retrotransposons were identified in species of Brachypodium (Bd, chr1_

6 70915934..70928501), wheat (Ta, FN564426_562537..573702), barley (Hv,

7 AC250228_46960..58979), rice (Os, AP008246_54271..66260), maize (Zm,

8 AF448416_48249..61044) and sorghum (Sb, chr9_9757379..9770073) respectively. The

9 boundaries (30 bp from the 5' and 3' end, respectively) of the LTRs were used for

10 alignment. The numbers on right indicate the length of 5' and 3' LTR for each

11 retrotransposon.

12 


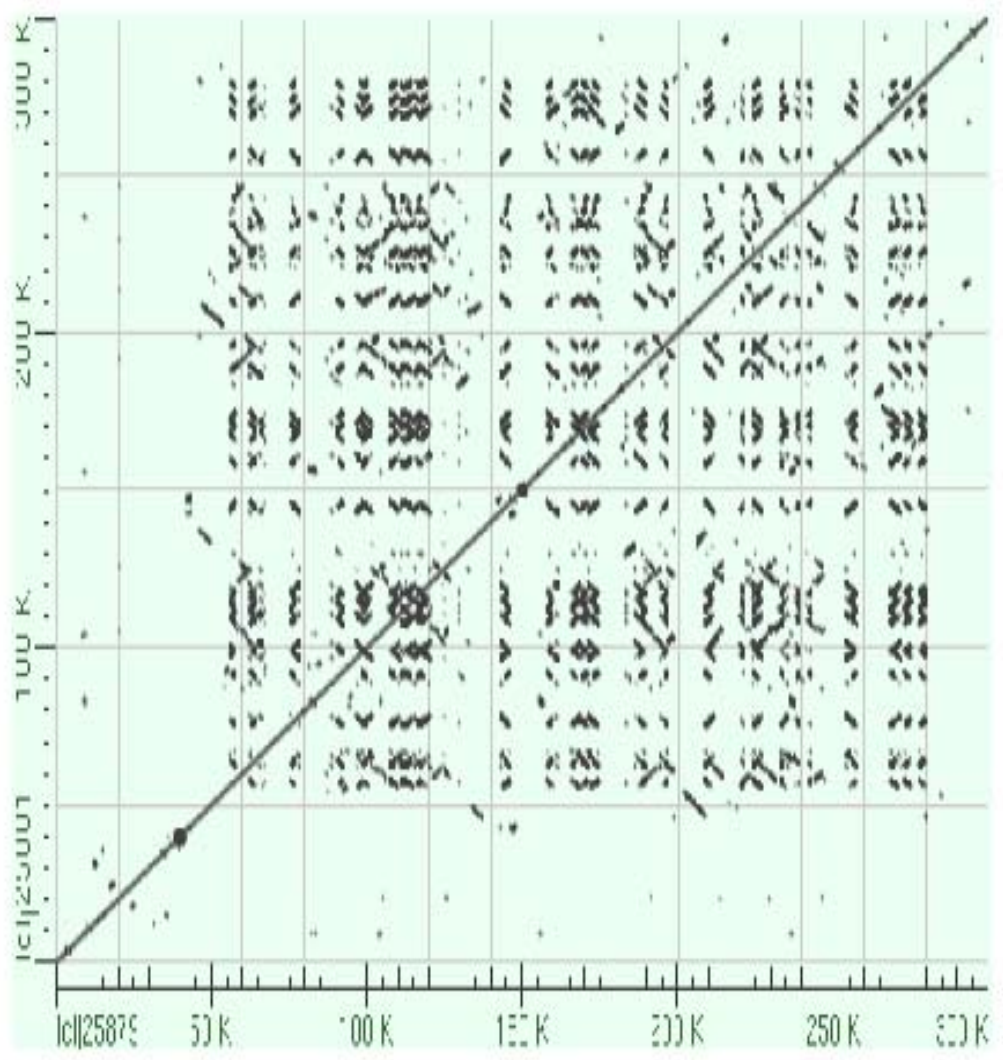

Fig. S1

Fig. S1 The dot matrix view of self alignment of the BAC DB069J23. 